\title{
Modelling infrastructure interdependency at a local scale: value, methodologies and challenges
}

\author{
$\underline{\text { Samiul Hasan }}^{\mathrm{a}}$, Fahim N. Tonmoy ${ }^{\mathrm{b}}$ Greg Foliente $^{\mathrm{a}}$ and Abbas El-Zein ${ }^{\mathrm{c}}$ \\ ${ }^{a}$ Land \& Water Flagship, CSIRO; ${ }^{b}$ National Climate Change Adaptation Research Facility (NCCARF), \\ Griffith University; ' School of Civil Engineering, University of Sydney
}

Email: Samiul.Hasan@csiro.au

\begin{abstract}
Natural hazards such as floods, bushfires, cyclones or hurricanes, can cause significant damage that disrupts our infrastructure systems. Climate change is making such extreme events more frequent and more severe. In addition, infrastructure systems have become more interconnected and interdependent. By interconnected, we mean that infrastructure systems use each other's output and operate together to provide joint services. The interdependence of two systems or components, on the other hand, refers to the effect of a decline of the performance of one system or component on another. Hence, a disruption to one infrastructure system may propagate into others and eventually affect various services that are critical for the well-being of communities. In recent years, cascading failures of infrastructure systems at a national scale have attracted significant attention. However, our understanding of these failures at a local scale remains limited. During major disasters, communities frequently face the challenge of disruptions that are locally triggered and propagated. Therefore, applying a systems-based analytical approach is likely to be beneficial for local authorities when making decisions on infrastructure planning and operations. To this end, the ability to model inter-connectedness of local infrastructure systems needs to be strengthened. The goal of this paper is to discuss the value of applying a systems approach to the analysis of infrastructure systems and their interdependencies and present and appraise various methodologies that can be used in implementing such as an approach. The paper is divided into four parts.
\end{abstract}

First, fundamental elements of interdependency analysis are presented. The differences between interdependency modelling at national and local scales are discussed and illustrated. One important difference is that coarse spatial resolution of models at a national scale prevents them from yielding information that is useful for locally-triggered and locally-propagated disruptions. For example, in a national-scale model, the entire water or power distribution system for a local government area may be represented by a single node reflecting its role in, and effect on, the national network, without incorporating an understanding of its internal operation.

Second, we describe the likely decision-making contexts within which infrastructure planning and management are conducted. Different local stakeholders with diverse concerns related to investment, planning, designing, and operations and management of infrastructures are usually involved in, and/or affected by, infrastructure decision-making. These stakeholders include local governments, infrastructure operators and utility companies, local businesses, households, individuals and local communities.

Third, we review different methodologies available for modelling infrastructure interdependencies at a local scale. We discuss their suitability in light of the specific analysis goals and identify their respective strengths and weaknesses. We propose a preliminary framework for selecting appropriate methods for modelling infrastructure performance depending on the underlying decision-making context.

Finally, we discuss important challenges present when tackling interdependency issues at a local scale. These challenges include lack of a comprehensive methodological framework linking different models, lack of a consistent benchmark and relevant datasets for judging the suitability of a method, and lack of a better understanding of the broader socio-economic impacts of infrastructure disruptions on local communities.

Keywords: Infrastructure interdependency, local government, infrastructure planning, cascading failure 


\section{INTRODUCTION}

Over the last few decades, we have seen an increased number of natural disasters in the world affecting millions of people (Guha-Sapir et al. 2013). Natural hazards such as earthquakes, floods, bushfires, cyclones or hurricanes can cause significant damage to our infrastructure systems which may create short-lived or prolonged disruptions to vital services with significant financial, economic, environmental and human cost. Climate change is making such extreme events more frequent and more severe.

On the other hand, infrastructure systems have become more interconnected and interdependent. By interconnected, we mean that infrastructure systems use each other's output and operate together to provide joint services. The interdependence of two systems or components, on the other hand, refers to the effect of a decline of the performance of one system or component on another. Hence, a disruption to one infrastructure element may propagate into others and eventually affect various services that are critical for the well-being of communities. Critical infrastructures such as telecommunications, electric power generation and transmission, transportation, water supply systems and emergency services have become elements in a bigger system. Thus, a disruption in one infrastructure system can lead to ripple effects that affect other systems and, consequently, the well-being and economic prosperity of communities. Two relatively recent examples of infrastructure failures of this type include:

- The 2003 Northeastern America power blackout resulted in about 50 million people in the Northeastern and Midwestern US and Ontario, Canada losing electric power. Power cuts, in turn, caused a shutdown of water treatment plants and pumping stations. Hence, water supplies in the affected areas lost water pressure, which led to water contamination. Sewage spilled into waterways forcing local authorities to issue boil water orders affecting about 8 million people (Wilbanks et al. 2013).

- The 2012 Hurricane Sandy in Northeastern US caused massive failures in power supply, inundated tunnels and subway stations and streets, and paralysed air transportation and financial services. About 8.7 million customers were affected by power outages causing serious damage to wireless and Internet infrastructure. Power outages also affected oil and natural gas production and transportation closing down refineries, oil terminals and gas tanks, with pipelines becoming inoperable (Comes and Van de Walle 2014).

Understanding the extent of interdependency in national and regional critical infrastructure is crucial for developing a more robust grid of infrastructure systems (Rinaldi et al. 2001) and has attracted significant attention in recent years. Research on interdependency at a local scale, however, has been very limited (Hasan and Foliente 2015; Tonmoy and El-Zein 2013). Local authorities, infrastructure operators, businesses and local communities are the critical agents at this scale since it is they who usually oversee (i.e., plan, implement, operate, use) most local infrastructure systems such as electricity transmission, water supply, sewerage, roads etc. (see Table 1). These stakeholders frequently face the challenges of disruptions in the interconnected infrastructure systems during natural disasters (e.g., hurricane/cyclone, earthquake, tsunami etc.). Local authorities are also the primary agents responsible for adaptation of local infrastructure to the impacts of climate change (e.g., sea level rise, flooding, heat waves etc).

Given the array of stakeholders involved, it is sometimes difficult to understand the broader impacts and many ramifications of a given decision. Thus, applying a systems approach can be beneficial for local authorities when making decisions on infrastructure planning and operations. For this to happen, the ability to model the inter-connectedness of local infrastructure systems must be strengthened. Such modelling would allow local authorities to

a) optimize resource allocations for new infrastructure developments (i.e., appraisal of new development projects to identify the project with maximum socio-economic benefits) and

b) identify local critical infrastructure that needs to be protected during disasters.

However, incorporation of systems thinking into local infrastructure planning and operation decision-making is a relatively new paradigm and therefore analysis of suitability of different modelling approaches in this context is under researched (Hasan and Foliente 2015).

In this paper, we explore local-scale infrastructure interdependencies and the means by which they can be analysed. First, we present the fundamental elements of interdependency analysis and highlight the most important differences between analyses at local and national scales. Second, we describe the likely decisionmaking contexts of infrastructure decisions at local scale. Third, we review different methodologies available for modelling infrastructure interdependencies at a local scale and map them against the various decision- 
making contexts within which infrastructure systems are managed. Finally, we identify several challenges present when tackling interdependency issues at a local scale.

Note that the word "local" could be taken to refer to any subnational scale. Depending on context, goals and data availability, local could denote a unit as small as a few dozen households (e.g., smallest statistical unit in Australian or German censuses) and as large as a geographical area of hundreds or thousands of kilometres squared. However, in this paper, we adopt a working definition of "local" as the smallest geographical administrative boundary (e.g., local government area (LGA) in Australia; county in the USA).

\section{INFRASTRUCTURE DEPENDENCY AND INTERDEPENDENCY AT A LOCAL SCALE}

\subsection{Fundamental elements of interdependency analysis}

\section{Local infrastructure systems}

A local government authority (LGA) houses multiple infrastructure systems to serve its residents (Table 1). Each of these services (sewerage, water supply, roads, etc) relies on multiple components to function. We define these individual components as "infrastructure nodes", and a set of connected nodes providing a service as an "infrastructure system" (e.g., water supply infrastructure system). As an example, a substation is denoted as a component of electricity supply system while a specific substation located at a specific geographic location is denoted as an infrastructure node (Table 1). Finally we refer to a set of multiple systems (e.g., water supply, power supply, transportation etc) as an “infrastructure network” (Pederson et al. 2006; Rinaldi et al. 2001).

Table 1. Examples of local infrastructure systems and their components.

\begin{tabular}{|c|c|}
\hline $\begin{array}{c}\text { Examples of local infrastructure } \\
\text { system }\end{array}$ & $\begin{array}{l}\text { Examples of infrastructure components } \\
\text { (relevant for a local council) }\end{array}$ \\
\hline Electricity supply & Substation, distribution network \\
\hline Water treatment and supply & Treatment plant, water mains, trunk mains, pipe networks \\
\hline Waste water transport & Pumping station, gravity main, rising main \\
\hline $\begin{array}{l}\text { Telecommunication (e.g., cellular and } \\
\text { land phones, internet) }\end{array}$ & $\begin{array}{l}\text { Telecom base stations, towers, transmission stations, } \\
\text { underground fibre optics cable }\end{array}$ \\
\hline Road network & Roads, traffic control systems \\
\hline Health care system & Hospitals, age care facilities \\
\hline Emergency response services & Fire service, ambulance \\
\hline
\end{tabular}

\section{Dependency and interdependency of infrastructure systems}

An infrastructure node is said to be dependent, if its serviceability (i.e. its ability to fulfil its function) depends on that of another infrastructure node within the same infrastructure system. As an example, the serviceability of a downstream water main depends on its neighbouring upstream water main. On the other hand, interdependency denotes dependency between two nodes from different infrastructure systems (e.g., supply from one power station affects the serviceability of a connected water pump).

\subsection{Difference between interdependency modelling at a national and local scale}

Modelling objectives, data requirements as well as the complexity of interconnectedness of infrastructure systems are different at a national and a local scale. At a national scale, modelling objectives vary from understanding the interconnectedness among major infrastructure assets (e.g., national electricity assets, telecommunication and information hubs etc.) to scenario analysis of cascading failures of one or more of the critical national infrastructure systems (Rinaldi et al. 2001). The overarching objective is usually to maximise national security by identifying critical components and pathways of disruption that might lead to major breakdowns. Infrastructure analyses at a local scale usually aim to characterise the effects of a local (internal) or national (external) disruption on local infrastructure systems, with a level of details that allows adjustments to be made within the locality in question. The following example illustrates one of the many possible differences among models at national and local scales.

A hypothetical modelling exercise for identifying national critical assets for ensuring water security (of a country) will require a national-scale dataset of major water distribution systems, dams, reservoirs as well as any major national electricity grid that supports their operations. Apart from input, output and performance levels of these infrastructures, four types of dependency information among these infrastructures will be needed. They are physical (a reliance of material flow from one infrastructure to another), informational or cyber (reliance of transfer of information among infrastructures), geospatial (dependency based on physical proximity) and logical (other dependencies that do not fall under the first three categories). In such a context, the water infrastructure of an entire LGA is typically represented as a single node (with input, output and 
performance level). This means that no detailed information is generated by the model about the performance of that node in a way that is useful for its management. On the other hand, a modelling exercise with similar objectives for an LGA (i.e., local scale) typically describes the network of water mains, stations etc. in a way that allows scrutiny of the inner workings and vulnerabilities of the system.

Thus, the usefulness of the outputs of national scale models is limited as far as the management of local systems is concerned. This is mainly because the structure and nature of the dependencies as well as other data requirements (input, output and performance level) of local infrastructures can be narrowed down with further details than that can be done at a national scale. Specifically, logical dependencies are quite abstract at a national scale model but easier to represent at a local scale. Logical dependencies, mostly due to human decisions and actions, represent the influences of one infrastructure into another without being physically connected. For instance, the state of or perceived risks in one infrastructure could influence behaviors/operations in another infrastructure due to loss of confidence in supply, through competition for labor or market share, or due to shifts to alternate inputs as a result of price or regulatory changes. Although data availability is still a major constraint for developing models at a local scale, analytical methods can combine quantitative and semi-quantitative or qualitative approaches incorporating local expert knowledge.

\section{DECISION-MAKING CONTEXTS: MAJOR STAKEHOLDERS AND THEIR ROLES}

A number of stakeholders are typically involved in local infrastructure decision-making with different interests and concerns related to investment, planning, design, operation and management. These stakeholders include: (a) local governments, (b) infrastructure operators and utility companies, (c) local businesses, and (d) households, individuals and communities.

A local government in a city or town faces several challenges when making decisions about infrastructure systems. Below is a list of analytical goals that local government authorities commonly pursue and Infrastructure Interdependency Modelling (IIM) could support decision-making:

- Assess the vulnerability of critical infrastructure systems under the authority's jurisdiction or cojurisdiction and develop corresponding risk-management and adaptation strategies. IIM could help to identify infrastructure components that are crucial for maintaining overall services during a disruption in a system of infrastructures.

- Develop and maintain infrastructure assets (e.g., transport services through roads \& bridges; communication services; electricity, gas, water supply etc.); IIM could help optimise investment by identifying infrastructure developments likely to yield the highest socio-economic benefits while accounting for its impacts on other sectors.

- Plan for disaster scenarios and develop disaster mitigation, management and recovery plans so that disruptions in services can be minimized. IIM could help in understanding the socio-economic impacts of infrastructure failures across multiple sectors.

Utility companies typically have their own analytical requirements, which overlap with, but may differ from those of local authorities:

- Plan, design, and build new utility infrastructures and evaluate alternative options for a local community. Using IIM concepts, the performance of an infrastructure system or component, within a system of infrastructures, can be tested and optimised.

- Design risk mitigating measures preventing cascading failures and protecting assets. IIM can help in better understanding the impacts of a cascading failure.

- $\quad$ Provide services delivered through infrastructure assets (e.g., transport services through ports, roads and bridges; communication services; electricity, gas, and water supply etc.)

Finally, businesses, individuals, households and communities may need to make infrastructure-related choices, which generate their own analytical requirements:

- Develop business strategies and evaluate investment options.

- Assess the risks to a business operation under a major disruption.

- $\quad$ Plan and prepare for extreme events in order to preserve life and protect property.

\section{AVAILABLE MODELLING APPROACHES}

Four major approaches are available to users for modelling infrastructure interdependency at a local scale: (1) empirical approaches, (2) agent-based simulation approaches, (3) system dynamics approaches and (4) network-based approaches. 
Table 2 summarises examples of studies, in the literature, that have used each of these approaches. The approaches are described, including their strengths and weaknesses, here below.

\subsection{Empirical approaches}

Empirical analyses are based on historical failure data and expert judgments. They are usually performed in order to identify the vulnerability of infrastructure systems and elicit alternative risk mitigating strategies. For instance, using an event tree, Ezell et al. (2000) conducted a risk assessment analysis for a small municipal water distribution system in a hypothetical local town. Chang et al. (2014) used a probabilistic method and expert judgment to characterize infrastructure vulnerability and community resilience in Vancouver, Canada while taking into account infrastructure interdependencies.

One of the strengths of empirical approaches is that they are well grounded in historical data and local perspectives on risk. However, this advantage can also be a limitation since the analyses may miss modes of failure, not previously encountered and, consequently, which do not form part of the collective memory of experts and stakeholders. In addition, these approaches are difficult to use for scenario-based what-if analyses that involve projecting into the future.

Table 2. Interdependency studies based on different approaches at a local scale.

\begin{tabular}{|c|c|c|c|c|}
\hline Study & Objective & Major Stakeholders & Infrastructure Modelled & Method Used \\
\hline (Ezell et al. 2000) & $\begin{array}{l}\text { Risk and vulnerability } \\
\text { assessment and risk } \\
\text { management }\end{array}$ & Local government & $\begin{array}{l}\text { Water supply and treatment } \\
\text { system }\end{array}$ & Empirical \\
\hline (Barrett et al. 2010) & Evacuation planning & $\begin{array}{l}\text { Emergency response } \\
\text { organization }\end{array}$ & $\begin{array}{l}\text { Cell phone, transport network } \\
\text { and social network }\end{array}$ & Agent-based \\
\hline $\begin{array}{l}\text { CIP/DSS } \\
\text { (Steinberg et al. 2011) }\end{array}$ & $\begin{array}{l}\text { Consequence of disruptions to } \\
\text { infrastructure, risk and } \\
\text { vulnerability assessment, guide } \\
\text { risk mitigation strategies }\end{array}$ & $\begin{array}{l}\text { Local government and } \\
\text { industry }\end{array}$ & $\begin{array}{l}\text { Water, Information \& } \\
\text { Telecommunications, Energy, } \\
\text { Transportation, Banking and } \\
\text { Finance and others }\end{array}$ & System dynamics \\
\hline $\begin{array}{l}\text { EVA-INFRA-SD } \\
\text { (Tonmoy and El-Zein } \\
\text { 2013) }\end{array}$ & Vulnerability assessment & Local government & $\begin{array}{l}\text { Water and waste water } \\
\text { network }\end{array}$ & System dynamics \\
\hline (Wang et al. 2012) & $\begin{array}{l}\text { Risk and vulnerability } \\
\text { assessment }\end{array}$ & Utility companies & Power and water systems & Network-based \\
\hline (Rahman et al. 2011) & $\begin{array}{l}\text { Risk and vulnerability } \\
\text { assessment }\end{array}$ & $\begin{array}{l}\text { Utility companies, } \\
\text { emergency managers }\end{array}$ & Power and water systems & Network-based \\
\hline (Holden et al. 2013) & $\begin{array}{l}\text { Simulate the operation of } \\
\text { interdependent infrastructures }\end{array}$ & Local governments & $\begin{array}{l}\text { Water distribution and power } \\
\text { generation }\end{array}$ & Network-based \\
\hline
\end{tabular}

\subsection{Agent-based simulation approaches}

An agent-based simulation model adopts a bottom-up approach to analyse the complex architecture and adaptive behaviours of the components of infrastructure systems. Agent-based approaches are capable of scaling down to the level of a single component of an infrastructure system and representing the behaviour of a decision-maker and/or user of the system. Such methods can capture a range of interdependencies to a level of detail that is useful for a local scale application. In addition, they are well suited for scenario-based what-if analyses and in assessing the effectiveness of different risk-mitigation strategies. For instance, agent-based modelling has been used extensively in emergency evacuation, taking into account road networks and individual behaviour (e.g., Barrett et al., (2010).

Nevertheless, an agent-based approach has a number of limitations, most importantly: (1) specific assumptions about agent behaviour have to be made which are sometimes hard to justify and may misrepresent actual behaviour; (2) detailed datasets about infrastructure performance and agent behaviour are required for model calibration and validation; such data may not be available, may be difficult to collect or may be beyond the financial means of the analyst conducting the simulations.

\subsection{System dynamics based approaches}

System dynamics is a widely used approach for analysing the behaviour and structure of a complex system over time (Sterman 2001). Unlike agent-based simulation methods, it is a top down approach that requires a 
full and explicit representation of the key elements of a system and the quantitative relationships between them. System dynamics models work with three central concepts: stocks (the accumulation of key resources in a system), flows (the rates of change that alter those resources), and feedback loops (the non-linear relationships between stocks that affect their rates of change in time).

A disruptive event applied to a particular flow or stock in a systems dynamics model, allows the analyst to track its effects on stocks and flows throughout the remainder of the system and to identify unexpected behaviour that would not be observable through simple linear causal relationships. For instance, Tonmoy and El-Zein (2013) investigated the vulnerability to long-term sea level rise of the infrastructures of Shoalhaven city council, Australia. The study identified local critical infrastructure through a systems dynamics model so that council decision makers can prioritize their limited climate adaptation resources. The main drawback of system dynamics models is that they require extensive knowledge of system structure and access to performance data for model calibration - neither of which may be available in many practical situations.

\subsection{Network based approaches}

In this approach, individual infrastructure systems are usually described mathematically as networks that contain nodes and links. Unlike system dynamics approaches, here nodes typically represent physical assets (e.g., water towers or pumping stations, electricity substation etc.) that are connected by links (e.g., water pipes, transmission lines etc.) which are also physical assets. Thus, through network-based approaches, intuitive representations of infrastructures are possible by providing the detailed descriptions of their structures and flow patterns. In these approaches, the effect of the failure of an individual component can be modelled and the response of the infrastructure system can be determined. Network based approaches can be divided into two groups: (a) topology-based and (b) flow-based approaches.

Topology-based approaches generally study topological characteristics of interrelated infrastructures and use these understandings to assess the vulnerability of national scale infrastructure systems (Dueñas-Osorio et al. 2007). However, the utility of these approaches are limited, in a local context, since they only focus on topological characteristics and mostly ignore the functional relationships among the different components of the network (e.g., infrastructures can be dependent on one another even without any topological similarity). Flow-based methods (Holden et al. 2013), on the other hand, can capture the functional relationships of interdependent infrastructures, and provide more realistic descriptions of their mechanisms of operation. Therefore, flow-based approaches are more suitable for a local scale application than topology-based methods.

\subsection{Discussion}

Table 3 matches the approaches discussed above to selected decision-making contexts. The appropriateness of a method is judged based on our understanding of the types of decisions faced by the different stakeholders, the technical features and capabilities of the different methods, and past applications of the methods in similar contexts, as reviewed herein. For instance, a local government agency may be interested in developing an emergency management and recovery plan so that disruptions to lifeline services are minimized. For such contexts, agent-based simulation approaches, system dynamics approaches and network theory based approaches have been deployed in the past and may be suitable. Which of these is used will depend of course on the specific context, data availability, as well the labour and financial resources that can be expended on the analysis. Our understanding can be confirmed in future through a survey of local stakeholders and comparing the selected approaches for a common decision-making context.

Table 3. Decision-making contexts: local stakeholders and their roles and appropriate methods.

\begin{tabular}{|c|c|c|c|}
\hline Major stakeholder & Primary roles & Specific decision-making context & $\begin{array}{l}\text { Modelling } \\
\text { approaches }\end{array}$ \\
\hline \multirow{4}{*}{ Local government } & $\begin{array}{l}\text { Infrastructure investment } \\
\text { and development }\end{array}$ & $\begin{array}{l}\text { Assess the vulnerability of key infrastructures, develop mitigating } \\
\text { and adaptation plans for identified critical infrastructures. }\end{array}$ & M3, M4 \\
\hline & $\begin{array}{l}\text { Infrastructure services } \\
\text { supply/provision }\end{array}$ & Provide services delivered through infrastructure assets & M2, M3, M4 \\
\hline & $\begin{array}{l}\text { Infrastructure } \\
\text { management/operation }\end{array}$ & $\begin{array}{l}\text { Identify the potential risk for the local infrastructures critical for } \\
\text { maintaining urban services and identify the affected communities }\end{array}$ & M1, M4 \\
\hline & $\begin{array}{l}\text { Emergency response and } \\
\text { management }\end{array}$ & $\begin{array}{l}\text { Plan for disaster scenarios and develop disaster management and } \\
\text { recovery plans so that disruptions in services can be minimized }\end{array}$ & M2, M3, M4 \\
\hline Utility companies & $\begin{array}{l}\text { Infrastructure services } \\
\text { supply/provision }\end{array}$ & $\begin{array}{l}\text { Provide services delivered through infrastructure assets (e.g. } \\
\text { transport services through roads \& bridges; communication services; } \\
\text { electricity, gas, and water supply etc.) }\end{array}$ & M2, M3, M4 \\
\hline Local business & Management and operation & Assess the risks of an operation under a major disruption & M1, M2, M4 \\
\hline
\end{tabular}


Hasan et al., Infrastructure interdependency at local scale

Households or Disaster preparedness Plan and prepare to preserve life and property in extreme events M1, M2 individuals

M1- Empirical approaches, M2- Agent-based simulation approaches, M3- System dynamics approaches, and M4- Network-based approaches

\section{FUTURE CHALLENGES}

Infrastructure interdependency at a local scale is an important yet under-researched topic. We have shown in this paper that a number of approaches for modelling the performance of infrastructure systems at a local scale are available. However, several challenges must be overcome before such models are deployed in a scientifically rigorous way. Most critically, detailed datasets are needed in relation to the physical performances of infrastructure individual elements under various conditions of disruptions. Without such data, the models cannot be calibrated and validated. In addition, models must be adequately informed by quantitative and qualitative research on the dynamic interaction between infrastructures systems and human agents (users, managers, decision-makers), including the impact of disruptions on livelihood. The richer and stronger such research is, the better the models.

\section{REFERENCES}

Barrett, C., Beckman, R., Channakeshava, K., Huang, F., Kumar, V. S. A., and Marathe, A. (2010). "Cascading failures in multiple infrastructures: From transportation to communication network." Proceedings of the Fifth International CRIS Conference on Critical Infrastructures. Beijing.

Chang, S. E., McDaniels, T., Fox, J., Dhariwal, R., and Longstaff, H. (2014). "Toward Disaster-Resilient Cities: Characterizing Resilience of Infrastructure Systems with Expert Judgments." Risk Analysis, 34(3), 416-434.

Comes, T., and Van de Walle, B. "Measuring Disaster Resilience: The Impact of Hurricane Sandy on Critical Infrastructure Systems." Proc., Proceedings of the 11th International ISCRAM Conference.

Dueñas-Osorio, L., Craig, J. I., and Goodno, B. J. (2007). "Seismic response of critical interdependent networks." Earthquake Engineering and Structural Dynamics, 36(2), 285-306.

Ezell, B. C., Farr, J. V., and Wiese, I. (2000). "Infrastructure risk analysis of municipal water distribution system." Journal of Infrastructure Systems, 6(3), 118-122.

Guha-Sapir, D., Hoyois, F., and Below, R. (2013). "Annual Disaster Statistical Review 2012: The Numbers and Trends."Brussels, Belgium.

Hasan, S., and Foliente, G. (2015). "Modeling infrastructure system interdependencies and socioeconomic impacts of failure in extreme events: emerging R\&D challenges." Natural Hazards, 78(3), 2143-2168.

Holden, R., Val, D. V., Burkhard, R., and Nodwell, S. (2013). "A network flow model for interdependent infrastructures at the local scale." Safety Science, 53(0), 51-60.

Kjølle, G. H., Utne, I. B., and Gjerde, O. (2012). "Risk analysis of critical infrastructures emphasizing electricity supply and interdependencies." Reliability Engineering and System Safety, 105, 80-89.

Pederson, P., Dudenhoeffer, D., Hartley, S., and Permann, M. (2006). "Critical infrastructure interdependency modeling: a survey of US and international research." Idaho National Laboratory, 1-20.

Rahman, H. A., Armstrong, M., Marti, J. R., and Srivastava, K. D. (2011). "Infrastructure interdependencies simulation through matrix partitioning technique." International journal of critical infrastructures, 7(2), 91-116.

Rinaldi, S. M., Peerenboom, J. P., and Kelly, T. K. (2001). "Identifying, understanding, and analyzing critical infrastructure interdependencies." IEEE Control Systems Magazine, 21(6), 11-25.

Steinberg, L. J., Santella, N., and Zoli, C. B. (2011). "Baton Rouge post-Katrina: The role of critical infrastructure modeling in promoting resilience." Homeland Security Affairs 7: Article 7.

Sterman, J. D. (2001). "System Dynamics Modeling: TOOLS FOR LEARNING IN A COMPLEX WORLD." California management review, 43(4).

Tonmoy, F. N., and El-Zein, A. "Vulnerability of infrastructure to Sea Level Rise: A combined outranking and system-dynamics approach." Proc., European Safety and Reliability (ESREL 2013), CRC Press, $2407-$ 2414.

Wang, S., Hong, L., and Chen, X. (2012). "Vulnerability analysis of interdependent infrastructure systems: A methodological framework." Physica A: Statistical Mechanics and its Applications, 391(11), 33233335 .

Wilbanks, T., Fernandez, S., Backus, G., Garcia, P., Jonietz, K., Kirshen, P., Savonis, M., Solecki, W., and Toole, L. (2013). "Climate change and infrastructure, urban systems, and vulnerabilities." Technical Report For The US Department of Energy in Support of the National Climate Assessment. 